\title{
Treatment of Congenital Chylothorax Using High-Dose Octreotide
}

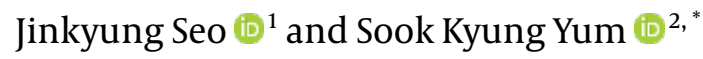 \\ ${ }^{1}$ Department of Pediatrics, College of Medicine, The Catholic University of Korea, Seoul, Korea \\ ${ }^{2}$ Division of Neonatology, Department of Pediatrics, College of Medicine, The Catholic University of Korea, Seoul, Korea \\ "Corresponding author: Division of Neonatology, Department of Pediatrics, College of Medicine, The Catholic University of Korea, Seoul, Korea. Email: cookieyyum@gmail.com
}

Received 2020 July 04; Revised 2020 September 01; Accepted 2020 September 04

\begin{abstract}
Introduction: Neonatal chylothorax is a rare and potentially life-threatening condition with a reported incidence of 1 in 5,800 24,000 and a high mortality rate of up to $64 \%$. Octreotide is one of the treatment options available to reduce both the splanchnic blood flow and the intestinal secretion of electrolytes and water. However, there is no uniform guideline for the optimal dosage of octreotide in the treatment of congenital chylothorax.

Case Presentation: We present the case of a neonate diagnosed with congenital chylothorax. At birth, the neonate manifested severe respiratory distress warranting cardiopulmonary resuscitation for $25 \mathrm{~min}$. During admission, intravenous octreotide treatment was initiated and feeding was changed from breast milk to a medium-chain triglyceride-enriched formula. Bilateral hilar enlargement and diffusely increased opacities waxed and waned, and we gradually increased the octreotide dosage daily by $1 \sim 2$ $\mathrm{mcg} / \mathrm{kg} / \mathrm{h}$. After 3 days of octreotide administration at the rate of $20 \mathrm{mcg} / \mathrm{kg} / \mathrm{h}$, chest x-ray showed regression of pleural effusion. The patient was discharged with full bottle feeding achieved.

Conclusions: High-dose octreotide therapy (with doses up to $20 \mathrm{mcg} / \mathrm{kg} / \mathrm{h}$ ) may be recommended for patients with idiopathic congenital chylothorax. However, patients should be carefully monitored for side-effects such as hyperglycemia, necrotizing enterocolitis, transient hypothyroidism, and ileus.
\end{abstract}

Keywords: Congenital Chylothorax, Idiopathic Chylothorax, Octreotide

\section{Introduction}

Neonatal chylothorax is a rare and potentially lifethreatening condition with a reported incidence of 1 in $5,800-24,000$ and a high mortality rate of up to $64 \%$ (1). The diagnosis is established by fluid analysis, including triglyceride content $\geq 1.1 \mathrm{mmol} / \mathrm{L}$ and a total cell count of $\geq 1000$ cells $/ \mathrm{mm}^{3}$ or $80 \%$ lymphocytes (2).

Octreotide is one of the treatment options available to reduce both the splanchnic blood flow and the intestinal secretion of electrolytes and water. However, there is no uniform guideline for the optimal dosage of octreotide in the treatment of congenital chylothorax (CC). Here, we report a case CC with high-dose octreotide $(20 \mathrm{mcg} / \mathrm{kg} / \mathrm{h})$ therapy.

\section{Case Presentation}

A male neonate was delivered at 34 weeks' gestation by vaginal delivery. The birth weight was $2690 \mathrm{~g}$, and the Apgar scores were 1 at $1 \mathrm{~min}$ and 1 at $5 \mathrm{~min}$. There was no significant maternal medical history except for latent tuberculosis. At 20 weeks of gestation, pleural effusion of 3 - 5 mm was detected in the right pleural space, and at 31 weeks of gestation, the amount of pleural effusion was increased and polyhydramnios was detected. At 34 weeks' gestation, the increase in pre-existing pleural effusion accounted for up to two-thirds of the right thorax.

At birth, the neonate manifested severe respiratory distress warranting cardiopulmonary resuscitation (CPR) for $25 \mathrm{~min}$. The chest $\mathrm{x}$-ray (Figure $1 \mathrm{~A}$ ) revealed bilateral whiteout of the lung field, which was more severe in the left lung than in the right side, prompting immediate chest tube insertion of the left chest (Figure 1B). Drained pleural effusion revealed a straw-colored fluid with the following composition: white blood cells (WBCs), 10560 cells/mm³ $(90 \%$ lymphocytes), and triglycerides, $7 \mathrm{mg} / \mathrm{dL}$. Total parenteral nutrition under nil per os (NPO) was maintained until day 16 , when trophic feeding with breast milk via oro-gastric tube was initiated.

On day 20, after progressive feeding for 4 days, the pleural effusion became turbid with the following composition: WBCs, 20,000 cells/mm3 (87\% lymphocyte); and triglycerides, $423 \mathrm{mg} / \mathrm{dL}$. Lymphoscintigraphy revealed probable lymphatic leakage in the thorax (Figure 1C). 

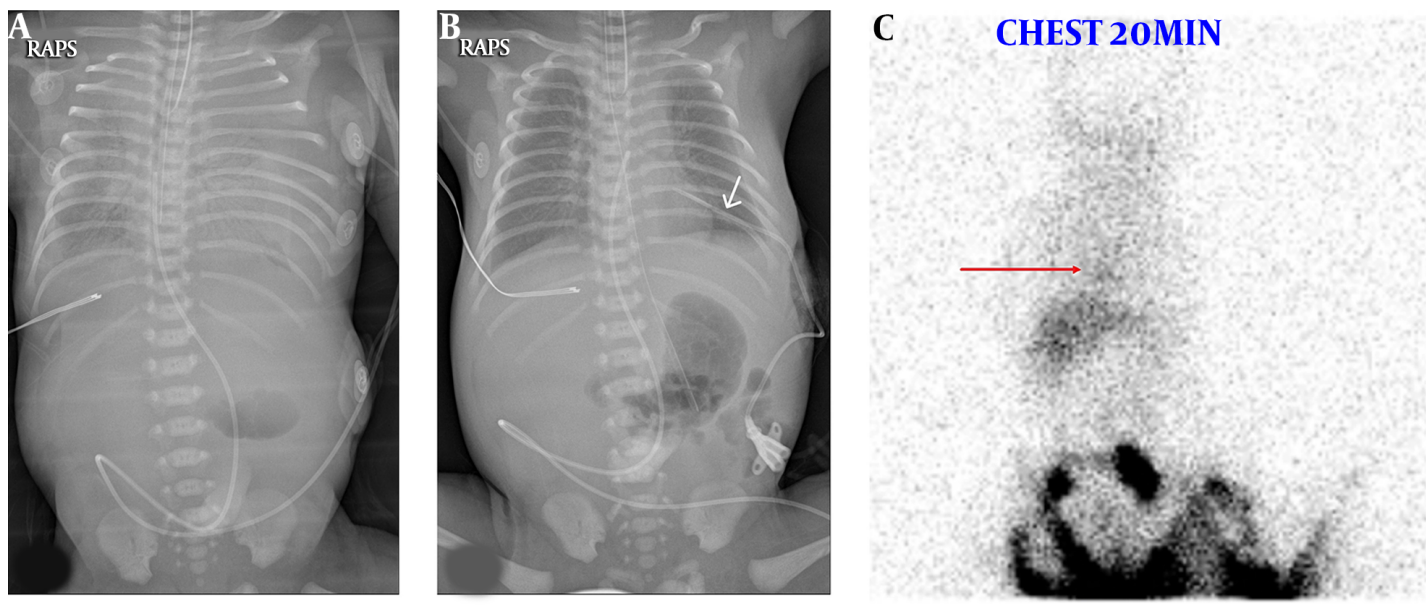

D

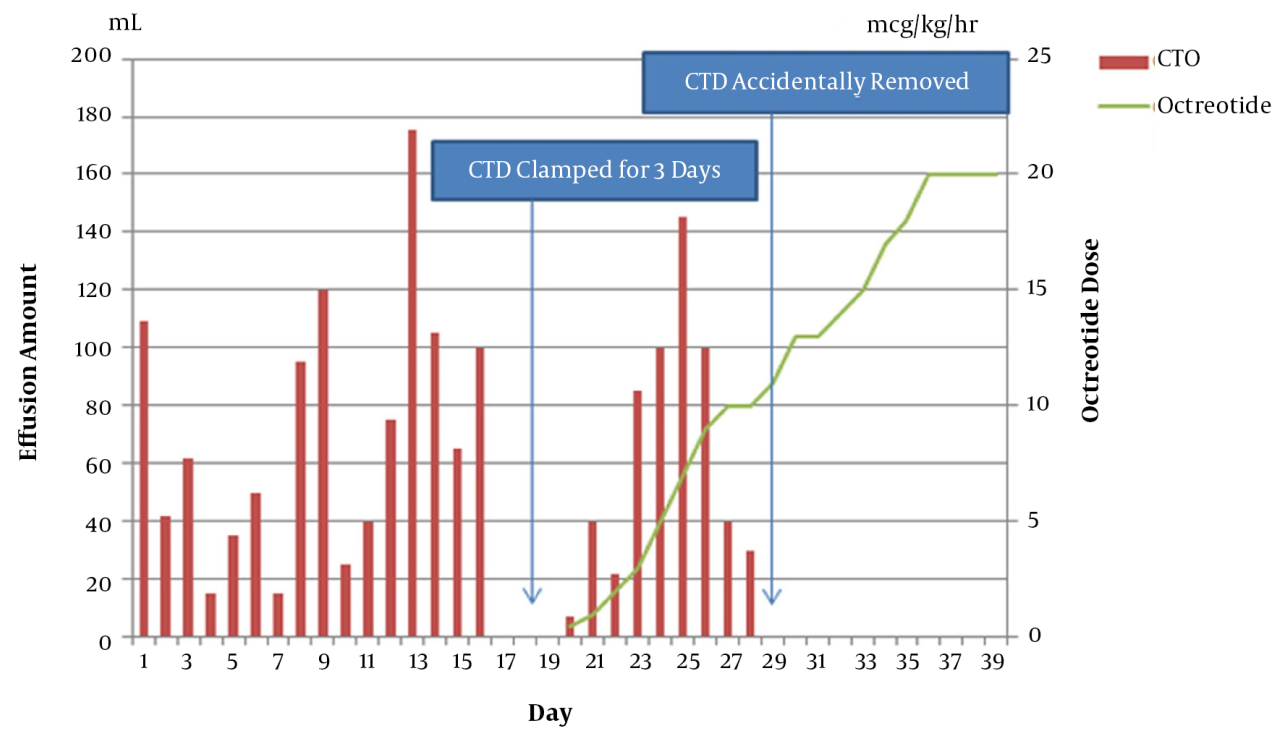

Figure 1. A, Bilateral pleural effusion before; and after B, intercostal chest tube drain insertion; C, lymphoscintigraphy revealed heart blood pooling activity (arrow), implying probable lymphatic leakage in the thorax; D, amount of pleural effusion and octreotide infusion dose.

Intravenous octreotide treatment with a beginning dose of $1 \mathrm{mcg} / \mathrm{kg} / \mathrm{h}$ was initiated and feeding was changed from breast milk to a medium-chain triglyceride-enriched formula. We gradually increased the octreotide dosage daily by $1 \sim 2 \mathrm{mcg} / \mathrm{kg} / \mathrm{h}$. Bilateral hilar enlargement and diffusely increased opacities waxed and waned, but the patient was tolerable under high-flow nasal cannula after extubation. On day 28 , the inserted chest tube was accidentally removed. The daily effusion amount is shown in Figure 1D.

On day 39, chest x-ray showed regression of pleural effusion after 3 days of octreotide administration at the rate of $20 \mathrm{mcg} / \mathrm{kg} / \mathrm{h}$, which was increased following parental consent. On day 41 , oxygen supplementation was completely stopped. On day 44 , we started tapering octreotide by $1 \sim 2 \mathrm{mcg} / \mathrm{kg} / \mathrm{h}$ daily, and on day 51 , octreotide was withheld without a problem. The patient did not reveal any signs of side effects, such as hyperglycemia, necrotizing enterocolitis, transient hypothyroidism, or ileus during octreotide treatment, even at higher doses (3). The patient was discharged on day 67 , with full bottle feeding achieved.

Congenital chylothorax is sometimes associated with Turner's or Noonan syndrome, trisomy 21, and other rare syndromes (4). All chromosomal and genetic evaluations of our patient were reported to be normal. In many cases such as the one reported here, the etiology of the CC is un- 
certain and is believed to be caused by abnormal thoracic or pulmonary system, which is designated as idiopathic CC.

\section{Discussion}

In neonates, chylothorax occurs when the thoracic duct is injured during birth trauma, cardiothoracic surgery, or great vessel thrombosis (5). It could also occur in dysmorphic syndromes, such as Turner or Noonan syndrome (4). In many situations, the etiology of neonatal chylothorax is uncertain and is believed to be caused by abnormal thoracic or pulmonary system, which is termed idiopathic CC (6), as reported in our case study. The patient's pleural effusion was discovered at 20 weeks' gestation, with normal karyotype and microarray results. Lymphoscintigraphy revealed probable lymphatic leakage in the thorax, suggesting a diagnosis of idiopathic CC.

Currently, no uniform guidelines are available for the treatment of neonatal chylothorax. The use of octreotide for the management of CC was first reported by Young et al. (7). Octreotide is one of the treatment options available to reduce both the splanchnic blood flow and the intestinal secretion of electrolytes and water (3).

This strategy leads to reduction in gastric, pancreatic, and intestinal secretions as well as intestinal absorption, resulting in reduced flow of chyle (8). However, there is no uniform guideline for the optimal dosage of octreotide in the treatment of CC.

Bellini's systematic review on the usage of octreotide based on 39 articles reported until October 2017, revealed that octreotide was effective in $47 \%$ of patients treated with various octreotide regimens with a median maximum dose of $7.6 \mathrm{mcg} / \mathrm{kg} / \mathrm{h}$ (9). Saito et al. (10) reported the successful usage of high-dose octreotide infusion therapy $(20 \mathrm{mcg} / \mathrm{kg} / \mathrm{h})$ in three neonatal cases of persistent chylothorax. Our report is similar to that of Saito's in that the chylothorax was resolved with octreotide infusion therapy (20 $\mathrm{mcg} / \mathrm{kg} / \mathrm{h})$. However, our report was different in that our patient was not treated with any procedure or surgery before the development of chylothorax. However, the severe chylothorax led to CPR of the neonate for $25 \mathrm{~min}$ after birth due to the unpredictable and rapid increase in pleural effusion compared with the amount identified via antenatal ultrasound several hours prior to delivery.

High-dose octreotide therapy (doses up to 20 $\mathrm{mcg} / \mathrm{kg} / \mathrm{h}$ ) is recommended for patients diagnosed with idiopathic CC. However, patients should be carefully monitored for possible side effects. Further large-scale population studies are needed to establish appropriate guidelines for the treatment of neonatal chylothoraces, including validation of various dosages of octreotide infusion.

\section{Footnotes}

Authors' Contribution: JS wrote the initial draft of the manuscript. SY critically reviewed and revised the manuscript. All authors read and approved the final manuscript.

Conflict of Interests: The authors declare no conflict of interest.

Ethical Approval: This study was approved by the Institutional Review Board (IRB) of the Catholic University of Korea, Seoul St Mary's Hospital (IRB no.: KC20ZISI0361).

Funding/Support: There is no funding support.

Informed Consent: We carried out the study under the agreement of the patients of the neonate. The parents were explained about high dose octreotide therapy and possible side effects before starting the treatment.

\section{References}

1. Bialkowski A, Poets CF, Franz AR, Erhebungseinheit fur seltene padiatrische Erkrankungen in Deutschland Study G. Congenital chylothorax: a prospective nationwide epidemiological study in Germany. Arch Dis Child Fetal Neonatal Ed. 2015;100(2):F169-72. doi: 10.1136/archdischild-2014-307274. [PubMed: 25480460].

2. Battin MR, Yan J, Aftimos S, Roberts A. Congenital chylothorax in siblings. BJOG. 2000;107(12):1516-8. doi: 10.1111/j.1471-0528.2000.tb11678.x. [PubMed: 11192110].

3. Roehr CC, Jung A, Proquitte H, Blankenstein O, Hammer H, Lakhoo $\mathrm{K}$, et al. Somatostatin or octreotide as treatment options for chylothorax in young children: a systematic review. Intensive Care Med. 2006;32(5):650-7. doi: 10.1007/s00134-006-0114-9. [PubMed: 16532329].

4. Tutor JD. Chylothorax in infants and children. Pediatrics. 2014;133(4):722-33. doi: 10.1542/peds.2013-2072. [PubMed: 24685960].

5. van Straaten HL, Gerards LJ, Krediet TG. Chylothorax in the neonatal period. Eur J Pediatr. 1993;152(1):2-5. doi: 10.1007/BF02072505. [PubMed: 8444200].

6. Beghetti M, La Scala G, Belli D, Bugmann P, Kalangos A, Le Coultre C. Etiology and management of pediatric chylothorax. $J$ Pediatr. 2000;136(5):653-8. doi: 10.1067/mpd.2000.104287. [PubMed: 10802499].

7. Young S, Dalgleish S, Eccleston A, Akierman A, McMillan D. Severe congenital chylothorax treated with octreotide. J Perinatol. 2004;24(3):200-2. doi: 10.1038/sj.jp.7211053. [PubMed: 15044932].

8. Rasiah SV, Oei J, Lui K. Octreotide in the treatment of congenital chylothorax. J Paediatr Child Health. 2004;40(9-10):585-8. doi: 10.1111/j.1440-1754.2004.00471.x. [PubMed: 15367160].

9. Bellini C, Cabano R, De Angelis LC, Bellini T, Calevo MG, Gandullia $\mathrm{P}$, et al. Octreotide for congenital and acquired chylothorax in newborns: A systematic review. J Paediatr Child Health. 2018;54(8):840-7. doi: 10.1111/jpc.13889. [PubMed: 29602276].

10. Saito M, Kamoda T. High Dose Octreotide for the Treatment of Chylothorax in Three Neonates. J Neonat Biol. 2016;5(2). doi: 10.4172/21670897.1000218 